\title{
1D and 2D-HSQC NMR: Two Methods to Distinguish and Characterize Heparin From Different Animal and Tissue Sources
}

\author{
Lucio Mauri ${ }^{1}$, Maria Marinozzi ${ }^{1}$, Nisarga Phatak ${ }^{2}$, Michael Karfunkle ${ }^{2}$, Kalib St. Ange ${ }^{3}$, \\ Marco Guerrini ${ }^{1 *}$, David A. Keire ${ }^{2 *}$ and Robert J. Linhardt ${ }^{3 *}$ \\ ${ }^{1}$ NMR Center, Istituto di Ricerche Chimiche e Biochimiche "G. Ronzoni," Milan, Italy, ${ }^{2}$ Division of Pharmaceutical Analysis, \\ Office of Testing and Research, Center for Drug Evaluation and Research, U.S. Food and Drug Administration, St. Louis, MO, \\ United States, ${ }^{3}$ Department of Chemistry and Chemical Biology, Center for Biotechnology and Interdisciplinary Studies, \\ Rensselaer Polytechnic Institute, Troy, NY, United States
}

OPEN ACCESS

Edited by:

Christian Ludwig,

University of Birmingham,

United Kingdom

Reviewed by:

Eduardo Prata Vilanova, Universidade Federal do Rio de Janeiro, Brazil Stefano Tiziani,

University of Texas at Austin, United States

${ }^{*}$ Correspondence: Marco Guerrini

guerrini@ronzoni.it David A. Keire david.keire@fda.hhs.gov

Robert J. Linhardt linhar@rpi.edu

Specialty section:

This article was submitted to Hematology, a section of the journal

Frontiers in Medicine

Received: 27 October 2018 Accepted: 07 June 2019

Published: 27 June 2019

Citation:

Mauri L, Marinozzi M, Phatak N, Karfunkle M, St. Ange K, Guerrini M, Keire DA and Linhardt RJ (2019) $1 D$ and 2D-HSQC NMR: Two Methods to

Distinguish and Characterize Heparin

From Different Animal and Tissue

Sources. Front. Med. 6:142

doi: 10.3389/fmed.2019.00142
The US Food and Drug Administration has encouraged the reintroduction of bovine heparin drug product to the US market to mitigate the risks of heparin shortages and potential adulteration or contamination of the primary source which is porcine heparin. Here, a 1D-NMR method was applied to compare heparin sodium of bovine intestinal origin with that of bovine lung, porcine, or ovine intestinal origin. The results showed that a simple 1D test using NMR signal intensity ratios among diagnostic signals of the proton spectra uniquely identified the origin of heparin and concomitantly could be used to assure the correct sample labeling. However, a limitation of the use of only mono-dimensional spectra is that these spectra may not provide sufficiently detailed information on the composition of heparin batches to adequately determine the quality of this complex product. As an alternative, a higher resolution quantitative 2D-HSQC method was used to calculate the percentage of mono- and disaccharides, distinguish the origin of heparin and, simultaneously, assess the heparin composition. The 2D-HSQC method is proposed to provide sufficient information to evaluate the quality of industrial production process used to make the drug substance. Together, the 1D and 2D data produced by these measurements can be used to assure the identity and purity of this widely used drug.

Keywords: heparin, NMR, HSQC, pharmacopeia, animal origin

\section{INTRODUCTION}

Heparin, one of the world's most widely-sold polysaccharide drugs and included in the World Health Organization's "Essential Drugs List" (1), is used for the treatment and prevention of thrombosis and is the anticoagulant of choice during cardio-pulmonary bypass or for hemodialysis. Until the 50's, bovine lung was the main source material for the large-scale heparin production, after which bovine lung tissue was largely replaced by porcine mucosa (2). Subsequently, in the late 1980s there was a spike in the number of cases of bovine spongiform encephalopathy (BSE) in the United Kingdom. As a result of concerns with contamination of the heparin supply, bovine heparin was voluntarily withdrawn from the market, and currently porcine mucosa is the only source material for all heparin products approved in US and Europe (3). 
Following the "heparin crisis" of 2007-2008, when at least 81 deaths and hundreds of severe anaphylactoid reactions were linked to the presence of over-sulfated chondroitin sulfate (OSCS) in some heparin batches, FDA and EMA initiated a rapid revision of the existing pharmacopeia monographs (4, 5 ). In addition to including tests regarding the potency and more restrictive limits for impurities, proton nuclear magnetic resonance (1H-NMR) was introduced as an identity test. The NMR test allowed one to define the similarity of the test sample relative to a porcine heparin reference standard, as well as to examine if non-heparin signals could be possibly associated with impurities or contaminants (6).

Because China is responsible for roughly half of the world's pig production, about $60 \%$ of the heparin supply comes from this country. In recent years the US FDA has expressed significant interest in considering reintroduction of bovine heparin drug product to the US market to mitigate the risk of supply chain issues due to the lack of source material and to diversify the source of heparin drugs globally (7). The FDA, assisted by experts coming from non-profit organizations, industries and academic institutions, is investigating the structural differences between porcine, and bovine heparins and their possible clinical implications. Previous studies extensively demonstrated structural differences between heparin from different animal and organ sources. Particularly, porcine mucosa heparin (PMH) is characterized by higher 6-O-sulfation compared to bovine mucosa heparin $(\mathrm{BMH})(80 \%$ in $\mathrm{PMH}$ vs. $55 \%$ in $\mathrm{BMH}$ comparing the total amount of GlcNx,6S or $68 \%$ in $\mathrm{PMH}$ vs. $48 \%$ in $\mathrm{BMH}$ comparing the amount of GlcNS, 6S linked to IdoA2S) $(8,9)$ and different structures and distribution of antithrombin binding sequences (10). Despite the same animal source, bovine lung heparin $(\mathrm{BLH})$ differs from $\mathrm{BMH}$ with higher 2-O-, 6-O-, and $\mathrm{N}$-sulfation and lower content of GlcA and GlcNAc residues $(11,12)$. By contrast, Ovine mucosa heparin $(\mathrm{OMH})$ is more similar to $\mathrm{PMH}$, with the exception of slightly higher levels of sulfation in position 2 and 6 of glucosamine and in position 2 of iduronic acid and lower $\mathrm{N}$-acetylation $(13,14)$.

In 2017 bovine mucosal heparin was readmitted to the market in Brazil, requiring the drafting of a new specific monograph. The NMR identification test of this new monograph includes an acceptance criterion for $\mathrm{BMH}$ corresponding to the ratio among the integral values of anomeric signals of glucosamine 6-O-sulfated and 6-O-desulfated which is not satisfied by $\mathrm{PMH}$ spectra (15). In the present study an alternative method based on the measurements of the ratio between the intensity of diagnostic signals of the ${ }^{1} \mathrm{H}-\mathrm{NMR}$ spectrum was proposed. The method proposed here can distinguish $\mathrm{BMH}, \mathrm{PMH}, \mathrm{OMH}$, and $\mathrm{BLH}$ samples from one another, while the ANVISA approach is specific for $\mathrm{BMH}$ vs. $\mathrm{PMH}$.

Recently, quantitative 2D-heteronuclear single quantum coherence (HSQC) NMR spectroscopy was established as viable method to determine the mono and disaccharide composition of heparin and LMWH $(16,17)$. The study of the factors influencing the limit of detection, linearity, accuracy, and precision demonstrated the robustness of the method in assessing the quality of heparin (18). This method, calculating the percentage of monosaccharide and disaccharide building blocks,
TABLE 1 | Number of $1 \mathrm{H}-\mathrm{NMR}$ spectra per heparin origin and spectrometer frequency.

\begin{tabular}{lcccc}
\hline & BMH & PMH & OMH & BLH \\
\hline${ }^{1} \mathrm{H}$ at $500 \mathrm{MHz}$ & 39 & 39 & 6 & 7 \\
${ }^{1} \mathrm{H}$ at $600 \mathrm{MHz}$ & 20 & 19 & 6 & 7 \\
\hline
\end{tabular}

can distinguish the heparin source as well as identify possible structural modification of the heparin chains induced by the purification process, often undetectable in one-dimensional NMR data. The HSQC method, applied to libraries of $\mathrm{BMH}$, $\mathrm{PMH}, \mathrm{OMH}$, and BLH heparin batches coming from different suppliers provided a basis set of characteristics for each heparin source and of their structural variability.

\section{MATERIALS AND METHODS \\ Reagents and Starting Material}

Deuterium oxide $99.9 \%$, sodium dihydrogenphosphate hydrate $\left(\mathrm{NaH}_{2} \mathrm{PO}_{4} \cdot \mathrm{H}_{2} \mathrm{O}\right)$, disodiumhydrogen phosphate dihydrate $\left(\mathrm{Na}_{2} \mathrm{HPO}_{4} \cdot \mathrm{H}_{2} \mathrm{O}_{2}\right)$, and 3-(trimethylsilyl)propionic-2,2,3,3-d4 acid sodium salt (TSP) were purchased from Sigma-Aldrich (Milan, Italy). Deuterated EDTA d-16 98\% was obtained from Product Cambridge Isotope Laboratories, Inc.

Phosphate buffer solution was prepared as follows: $49.7 \mathrm{mg}$ of sodium dihydrogenphosphate hydrate $(0.36 \mathrm{mmol}), 202.9 \mathrm{mg}$ of disodium hydrogen phosphate dihydrate $(1.14 \mathrm{mmol})$, and $0.92 \mathrm{mg}$ deuterated EDTA d-16 $(0.003 \mathrm{mmol})$ were dissolved in $10 \mathrm{~mL}$ of water. The $\mathrm{pH}$ was checked at 7.1. The solution was distributed into $5 \mathrm{~mL}$ aliquots and then lyophilized. Each aliquot was dissolved in about $1 \mathrm{~mL}$ of $\mathrm{D} 2 \mathrm{O}$ and lyophilized again. Finally, the buffer was dissolved in $5 \mathrm{~mL}$ of deuterium oxide with $0.002 \%$ TSP (12 mM).

\section{Heparin Samples}

The heparin samples utilized in this study were obtained from 13 different producers. The samples included 39 porcine mucosa heparins, 39 bovine mucosa heparins, 6 ovine mucosa, and 7 from beef lung heparins. $20 \mathrm{BMH}, 2 \mathrm{PMH}$, and $1 \mathrm{BLH}$ were provided by USP, the remaining samples from Ronzoni Institute.

All the samples were characterized by ${ }^{1} \mathrm{H}$ and HSQC-NMR analysis. Table 1 summarizes the ${ }^{1} \mathrm{H}-\mathrm{NMR}$ spectra recorded for this study.

\section{Samples Preparation}

About $35 \mathrm{mg}$ of heparin sample were dissolved in a $0.6 \mathrm{ml}$ of phosphate buffer solution and transferred on a $5 \mathrm{~mm}$ NMR tube.

\section{${ }^{1} \mathrm{H}-$ NMR Method}

${ }^{1} \mathrm{H}-\mathrm{NMR}$ spectra were measured on a Bruker AVANCE III 600 $\mathrm{MHz}$ spectrometer or on a Bruker AVANCE III HD $500 \mathrm{MHz}$ spectrometer (Karlsruhe, Germany), equipped with $5 \mathrm{~mm}$ TCI cryogenic probes. The experiments were recorded at $298 \mathrm{~K}$ by using the Bruker library zg pulse sequence and the following parameters: number of scans 16, dummy scans 4, relaxation delay $12 \mathrm{~s}$, spectral width $16 \mathrm{ppm}$, transmitter offset $4.7 \mathrm{ppm}$. 


\section{Porcine mucosa Heparin (PMH)}

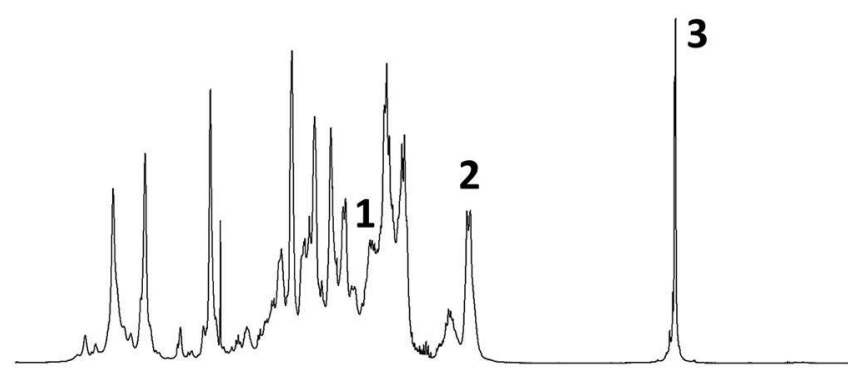

\section{Bovine mucosa heparin (BMH)}

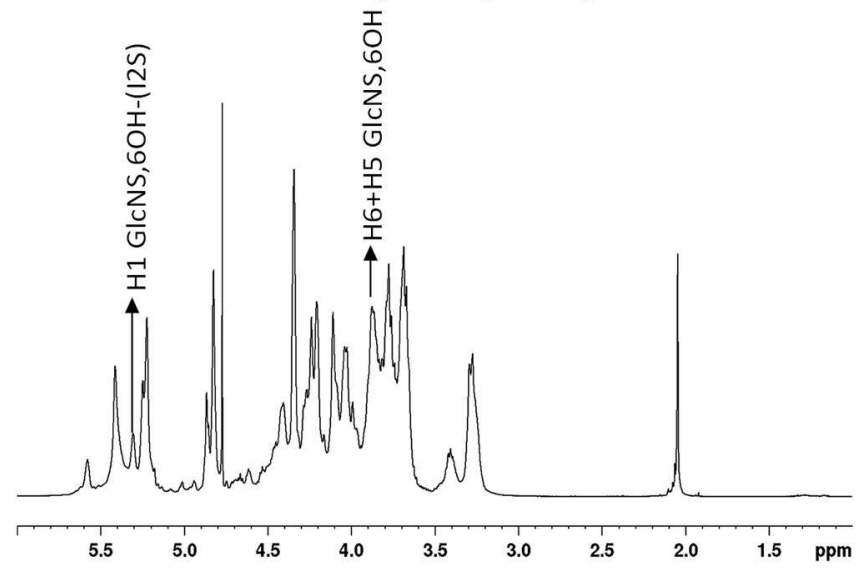

\section{Ovine mucosa heparin (OMH)}

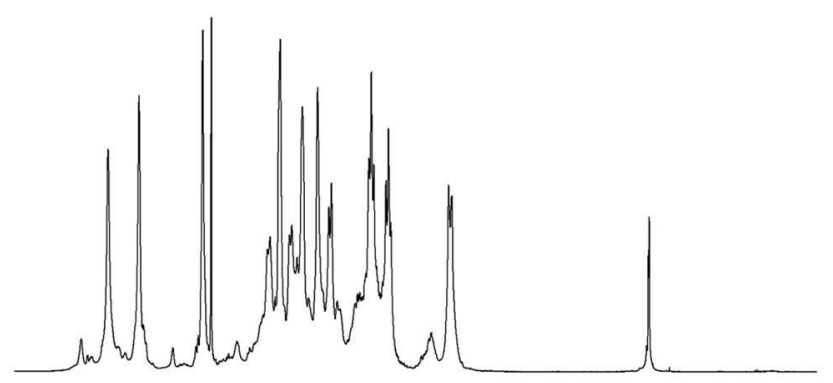

Bovine lung heparin (BLH)

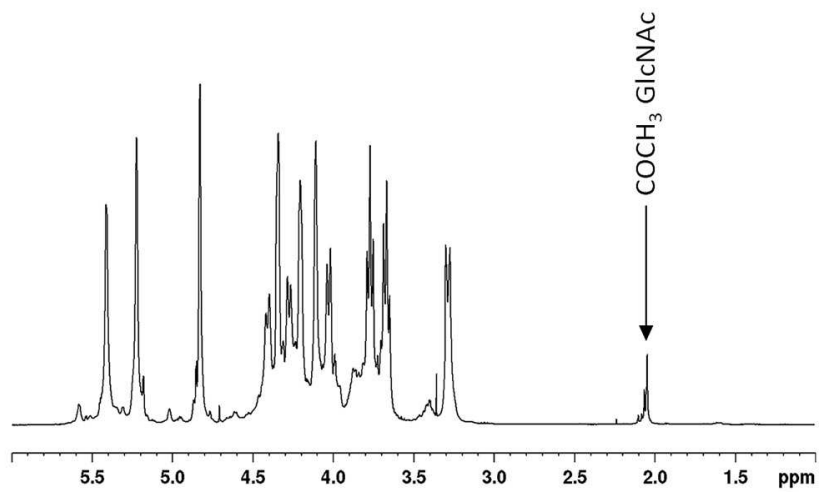

FIGURE 1 | $600 \mathrm{MHz}$ proton spectra of heparin samples extracted from different species/organ. Signals 1, 2, and 3, corresponding to H5 + H6 of 6-O-desulfated glucosamine, $\mathrm{H} 2$ of $\mathrm{N}$-sulfated glucosamine, and acetyl group of $\mathrm{N}$-acetylated glucosamine, respectively, were used as diagnostic peaks for the determination of the origin.

After exponential multiplication (line broadening of $0.3 \mathrm{~Hz}$ ), the spectra were Fourier transformed, phased, baseline corrected, and calibrated on the TSP signal.

The spectrum can be accepted only if the following test is satisfied: the width half height of TSP is $\leq 1.4 \mathrm{~Hz}$.

The intensity of the following signals was measured:

- Peak 1 at 3.87 ppm that corresponds to the H5/H6 of the $\mathrm{N}$-sulfated, 6-O-desulfated glucosamine (GlcNS, 6OH).

- Peak 2, the highest intensity signal between 3.33 and $3.20 \mathrm{ppm}$, that corresponds to the $\mathrm{H} 2$ of $N$-sulfated glucosamine (GlcNS,6X).

- Peak 3 at $2.05 \mathrm{ppm}$ that correspond to the methyl signal of $\mathrm{N}$-acetylated glucosamine $\left(\mathrm{COCH}_{3}\right)$.

The ratio $\mathrm{r}(1: 2)$ between peaks 1 and 2 , and the ratio $\mathrm{r}(3: 2)$ between peaks 2 and 3 were calculated and used to distinguish the different heparin sources.

\section{HSQC-NMR Method}

The $2 \mathrm{D}-{ }^{1} \mathrm{H},{ }^{13} \mathrm{C}$-HSQC spectra were measured on Bruker AVANCE III $600 \mathrm{MHz}$ spectrometer equipped with a $5 \mathrm{~mm}$ TCI cryoprobe, using the Bruker hsqcetgpsisp2.2 pulse sequence. The spectra were recorded at $298 \mathrm{~K}$ using the following acquisition parameters: number of scans 12 , dummy scan 16 , relaxation delay $2.5 \mathrm{~s}$, spectral width $8 \mathrm{ppm}$ (F2), and $80 \mathrm{ppm}$ (F1), transmitter offset $4.7 \mathrm{ppm}(\mathrm{F} 2)$ and $80 \mathrm{ppm}(\mathrm{F} 1),{ }^{1} \mathrm{~J}_{\mathrm{C}-\mathrm{H}}=150 \mathrm{~Hz} .1,024$ points were recorded for each of 240 increments (NUS of $75 \%$ of 320 increments). The FIDs were processed as follows: spectrum size 4096 (F2) and 1,024 (F1) (zero-filling in F2 and linear prediction in F1), squared cosine window multiplication in both dimensions and Fourier transform. The spectra were integrated using Topspin software version 3.5 (Bruker BioSpin, Rheinstetten, Germany) and the heparin composition was computed from the integral values as previously described (18).

\section{Statistical Methods}

Prediction intervals were computed assuming normal distributions (Kolmogorov-Smirnov tests gave $p>0.3$ ) of the data, using the formula:

$$
\left(\bar{x}-\tau_{0.995, n-1} \cdot s d \cdot \sqrt{1+1 / n}, \bar{x}+\tau_{0.995, n-1} \cdot s d \cdot \sqrt{1+1 / n}\right),
$$




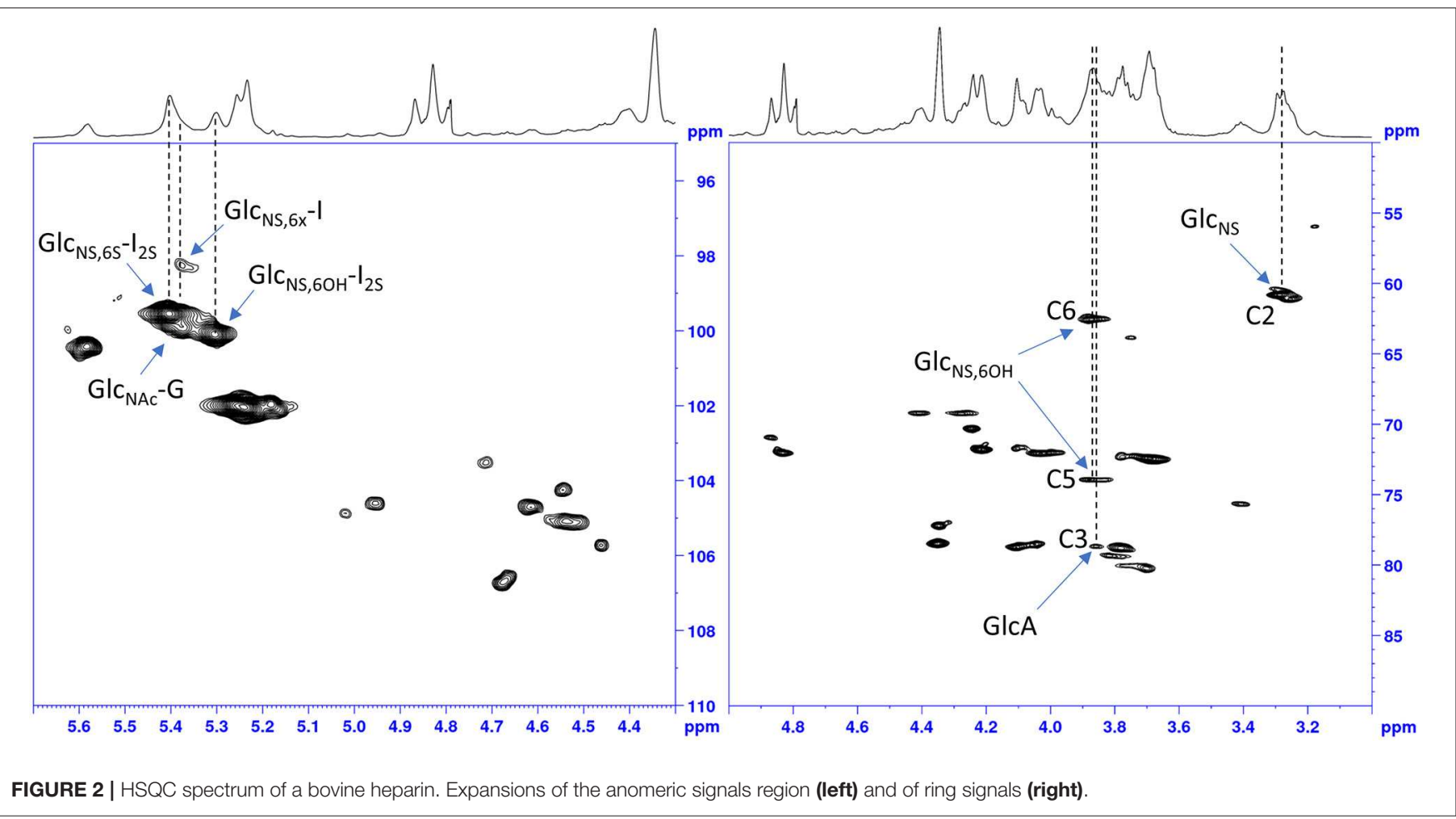

where $x$ and $s d$ are the mean and the standard deviation of the $n$ observations, and $\tau_{0.995, n-1}$ is the 0.995 th quantile of the Student's $t$-distribution with $n-1$ degrees of freedom.

Boxplot were produced as follows: the lower and upper limits of the box correspond to the 25 th and the 75 th percentiles. Called $I Q R$ the distance between these two limits, the ends of the boxplot vertical segments correspond to the lowest datum still within 1.5 IQR of the 25th percentile, and the highest datum still within 1.5 IQR of the 75th percentile. Data outside of the vertical segments were plotted as dots.

\section{RESULTS}

Proton NMR spectra of heparin show slightly different profiles according the animal/organ origin (Figure 1). Of the types tested here, proton NMR spectra of BMH have the most observable differences compared to other heparins. Particularly, the heparin signals at 5.31 and $3.87 \mathrm{ppm}$, corresponding to the $\mathrm{H} 1$ and $\mathrm{H} 5 / \mathrm{H} 6$ of the 6-O-desulfated glucosamine, respectively, had greater intensities in $\mathrm{BMH}$ spectra compared to those observed in the spectra of other heparin sources. This observation was consistent with the observation of lower 6-O-sulfation levels in bovine mucosa heparin described in previous studies $(8,19)$. The spectrum of bovine lung heparin (BLH) showed structural peculiarities compared other spectra, particularly evident in the lower intensity of the acetyl peak at $2.05 \mathrm{ppm}$. By contrast, proton spectra of $\mathrm{PMH}$ and $\mathrm{OMH}$ were more similar, even though a reduction of the acetyl peak intensity can be observed in the spectra of $\mathrm{OMH}$ compared to $\mathrm{PMH}$ data.
The idea to integrate diagnostic signals of carbon and proton NMR spectra to distinguish bovine and porcine heparin was first proposed by Casu et al. (8) and then by Tovar et al. (20) and $\mathrm{Fu}$ et al. (14). The identification test for bovine mucosa heparin, currently used by the drug regulatory agency of Brazil (15), uses the ratio between the integral values of proton anomeric signals belonging to glucosamine 6-O-sulfated and 6$O$-desulfated residues, with chemical shifts at 5.40 and $5.31 \mathrm{ppm}$, respectively. However, because the anomeric proton signal of GlcNS,6S used by the ANVISA method, at least at magnetic field lower than $600 \mathrm{MHz}$, partially overlaps with those of $N$-sulfated glucosamine linked to iduronic acid (GlcNS-I) and $\mathrm{N}$-acetyl glucosamine linked to glucuronic acid (GlcNAc-G) (Figure 2), we decided to use different signals which had less interference from other monosaccharides. As reference signals we chose the $\mathrm{H} 2$ of $N$-sulfated glucosamine (GlcNS) and the acetyl signal of $\mathrm{N}$-acetylated glucosamine (GlcNAc) which have chemical shift values of 3.28 and $2.04 \mathrm{ppm}$, respectively, and are well separated from the other signals (annotated peaks 2 and 3 of Figure 1). For a marker for the 6-O-desulfated glucosamine population, typical of $\mathrm{BMH}$, the $\mathrm{H} 5$ and $\mathrm{H} 6$ protons signals (3 protons) were used and were overlapped in the same peak at $3.87 \mathrm{ppm}$ (peak 1 of Figure 1). Although the $3.87 \mathrm{ppm}$ signal was also partially superimposed with the signal from $\mathrm{H} 3$ of the glucuronic acid (GlcA) (21), the sensitivity was better than that obtained from the use of the anomeric signal, which was due to just one proton (Figure 2).

The integral values of partially overlapped heparin signals can vary as a function of the magnetic field used, spectral resolution or by the natural structural variability of heparin (22). Moreover, 


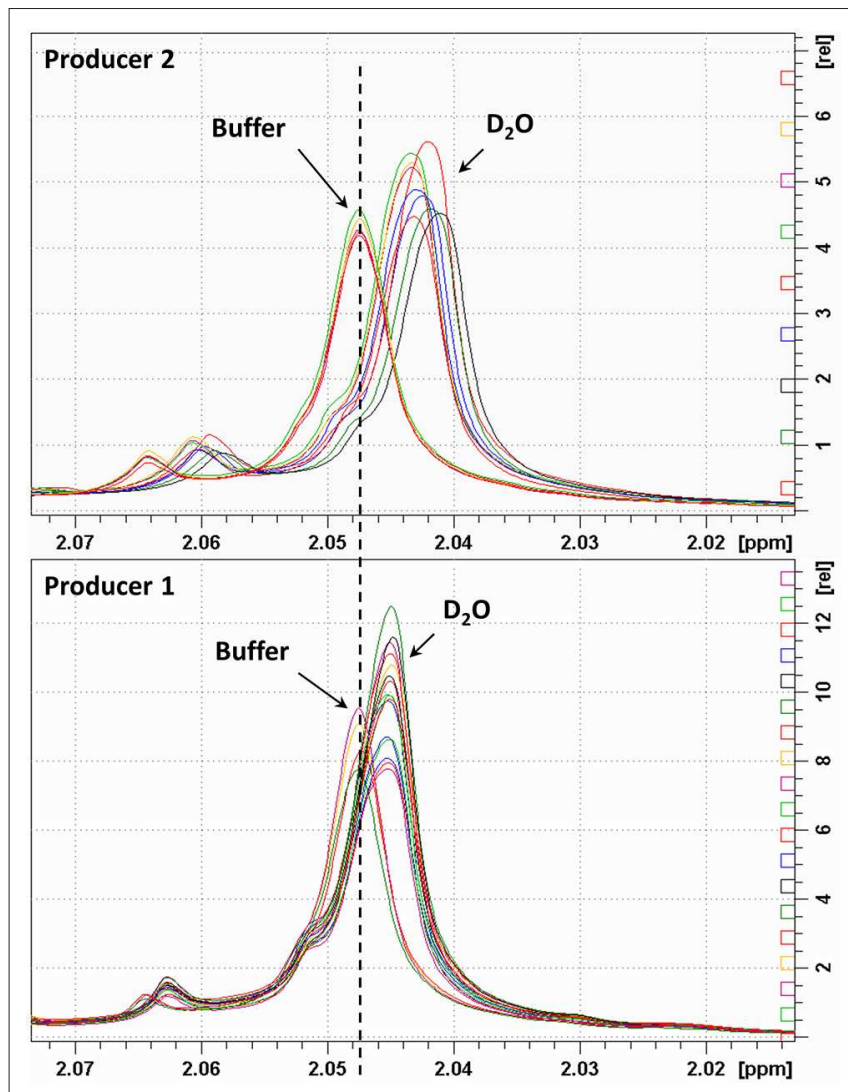

FIGURE 3 | Acetyl signal of heparin $1 \mathrm{H}-\mathrm{NMR}$ spectra registered in $\mathrm{D}_{2} \mathrm{O}$ or buffer. Top and bottom panels show samples of two different manufacturers.

the ANVISA method was designed to distinguish BMH from $\mathrm{PMH}$, while the method discussed here aims to differentiate $\mathrm{PMH}, \mathrm{BMH}, \mathrm{OMH}$, and BLH. For this reason, we evaluated the signal intensities instead of the integral values. Due to the polyelectrolyte characteristic of heparin, slight differences in the concentration, $\mathrm{pH}$ or ionic strength of the heparin solutions can induce small changes in chemical shift values. Figure 3 shows the acetyl signal of the proton spectra of several $\mathrm{PMH}$ samples from two different suppliers, measured in deuterium oxide or in phosphate buffer. The addition of buffer removes the small shifts observed in deuterium oxide, making the spectra more reproducible, and comparable by minimizing $\mathrm{pH}$ and ionic strength sources of variation. Moreover, to avoid variation of signal intensities due to bad spectral resolution from poor field homogeneity, a requirement of a minimum full width at half-height linewidth of the signal of deuterated trimethylsilylpropionic acid sodium salt (TSP), used as chemical shift reference, was introduced (see the Experimental Section).

\section{H-NMR Spectra}

Using the standardized conditions described in the experimental section, $39 \mathrm{BMH}, 39 \mathrm{PMH}, 6 \mathrm{OMH}$, and $7 \mathrm{BLH}$ samples were analyzed with the proposed ${ }^{1} \mathrm{H}$-NMR method at 500 and/or $600 \mathrm{MHz}$. The intensities of peaks 1 (3.87 ppm), 2 (3.28 ppm),

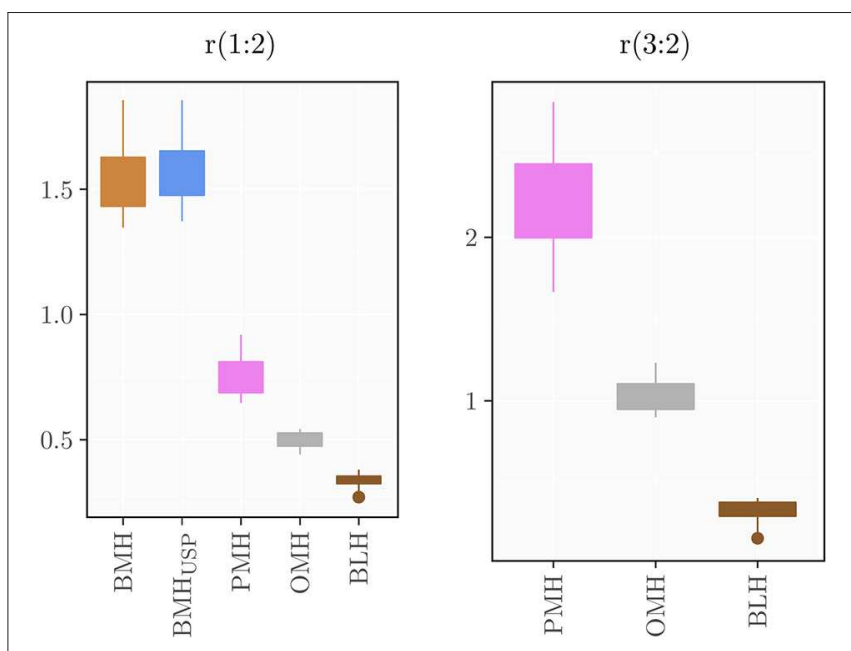

FIGURE 4 | Boxplots of the computed ratios $r(1: 2)$ and $r(3: 2)$ for the different heparin sources.

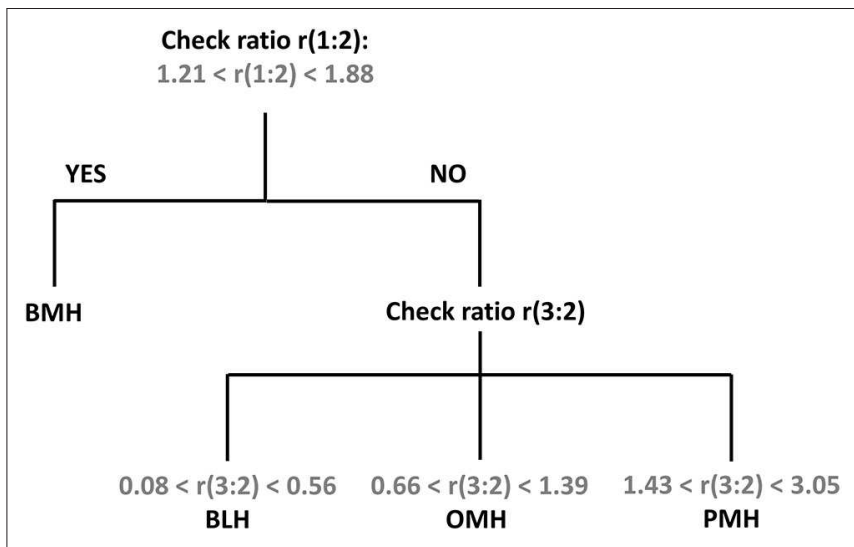

FIGURE 5 | Proposed scheme for the identification of heparin source from the signal ratios $r(1: 2)$ and $r(3: 2)$.

and $3(2.05 \mathrm{ppm})$ were measured and the ratios 1:2 and 3:2 were calculated (Supplementary Tables 1-6). Results, shown in Figure 4, indicate that a ratio of 1:2 clearly distinguishes $\mathrm{BMH}$ from the other heparin sources, whereas a ratio of $3: 2$ differentiates $\mathrm{PMH}, \mathrm{OMH}$, and $\mathrm{BLH}$. Accordingly, the scheme presented in Figure 5 can be used to identify heparin types from each group from these ratios: first check the 1:2 ratio is between 1.21 and 1.88 , to classify the sample as $\mathrm{BMH}$, otherwise check the 3:2 ratio to decide among $\mathrm{PMH}, \mathrm{OMH}, \mathrm{BLH}$, or an unknown source. The limits of Figure 5 correspond to prediction intervals with $99 \%$ probability (see Experimental section). The $\mathrm{PMH}$ and $\mathrm{OMH}$ interval separation was the smallest, confirming the similarity of heparins from these two sources. The results were only marginally affected by the magnetic field strength (500 or $600 \mathrm{MHz}$ ) so the scheme can be adopted independently of the instrument used.

A repeatability study was performed using a $\mathrm{PMH}$ heparin batch to determine the precision of the method. Six NMR tubes 
of the same sample were prepared, and proton spectra were recorded on each sample using 16 or 8 scans, respectively. Results summarized in the Supplementary Table 7 show that the CV\% of both ratios was $\leq 4 \%$ regardless the number of scans.

A series of $20 \mathrm{BMH}, 1 \mathrm{PMH}$, and $1 \mathrm{BLH}$ provided by USP were analyzed by ${ }^{1} \mathrm{H}-\mathrm{NMR}$ by two independent laboratories. Results obtained on $\mathrm{BMH}$ show a good comparability between the ranges and values obtained by the two laboratories (Table 2 and Supplementary Table 8). This was confirmed by a paired $t$-test on the $\mathrm{r}(1: 2)$ value of the BMH samples which gave a $p$ value of 0.45 . Both laboratories identified test samples (BLH and $\mathrm{PMH})$ as non-compatible with $\mathrm{BMH}[\mathrm{r}(1: 2) \leq 1]$. However, while

TABLE 2 | Range of signal intensity ratios calculated on $20 \mathrm{BMH}$ samples by two laboratories.

\begin{tabular}{cccccc}
\hline & & Range & BMH & PMH sample & BLH sample \\
\cline { 3 - 4 } & & $\min$ & $\max$ & & \\
\hline $\mathrm{r}(1: 2)$ & Lab 1 & $\mathbf{1 . 3 5}$ & $\mathbf{1 . 8 6}$ & 0.74 & 0.38 \\
& Lab 2 & $\mathbf{1 . 4 0}$ & $\mathbf{1 . 8 5}$ & 0.72 & 0.35 \\
$\mathrm{r}(3: 2)$ & Lab 1 & & & 2.30 & 0.40 \\
& Lab 2 & & & $1.37^{\star} / 2.15$ & 0.34 \\
\hline
\end{tabular}

One PMH and one BLH sample were used as test samples. *value measured on PMH by laboratory 2 from spectrum which does not comply with resolution requirement. $r_{-}(1: 2)$ of the BMH samples measured by two different laboratories are shown in bold. the BLH sample was correctly identified by both laboratories, laboratory 2 identified the $\mathrm{PMH}$ sample as $\mathrm{OMH}$, since $\mathrm{r}(3: 2)$ value (1.37) was within the range of mucosa ovine heparin. A more detailed analysis of the spectra reveals a lower spectral resolution of the $\mathrm{PMH}$ spectrum measured by laboratory 2, confirmed by the different width at half height of TSP between the two spectra (about $1 \mathrm{~Hz}$ and $5 \mathrm{~Hz}$, for laboratory 1 and 2, respectively) (Figures 6A,B). The $\mathrm{r}(3: 2)$ ratio value obtained from the spectrum measured by laboratory 2 on the same sample, comply with the resolution requirement (width at half height of TSP of $1.4 \mathrm{~Hz}$ ), was 2.15, therefore compatible with $\mathrm{PMH}$ sample (Figures 5, 6C). This confirms that the evaluation of the spectrum resolution using the width half height of the TSP signal is crucial for a correct identification of the heparin sources with the proposed method.

\section{HSQC Analysis}

Quantitative HSQC was recently applied to heparin and low molecular weight heparins (LMWHs) for calculating the percentage of monosaccharides and disaccharides by normalizing volumes with reference to the sum of volumes of signals corresponding to each monosaccharide type (glucosamines or uronic acids) and the same carbon proton pair type $(17,18)$. This validated analytical procedure can be used to assess the quality of industrial production in terms of presence of contaminants or chemical modifications, as well as to compare heparin of different manufacturers or to differentiate heparin of different sources (10).
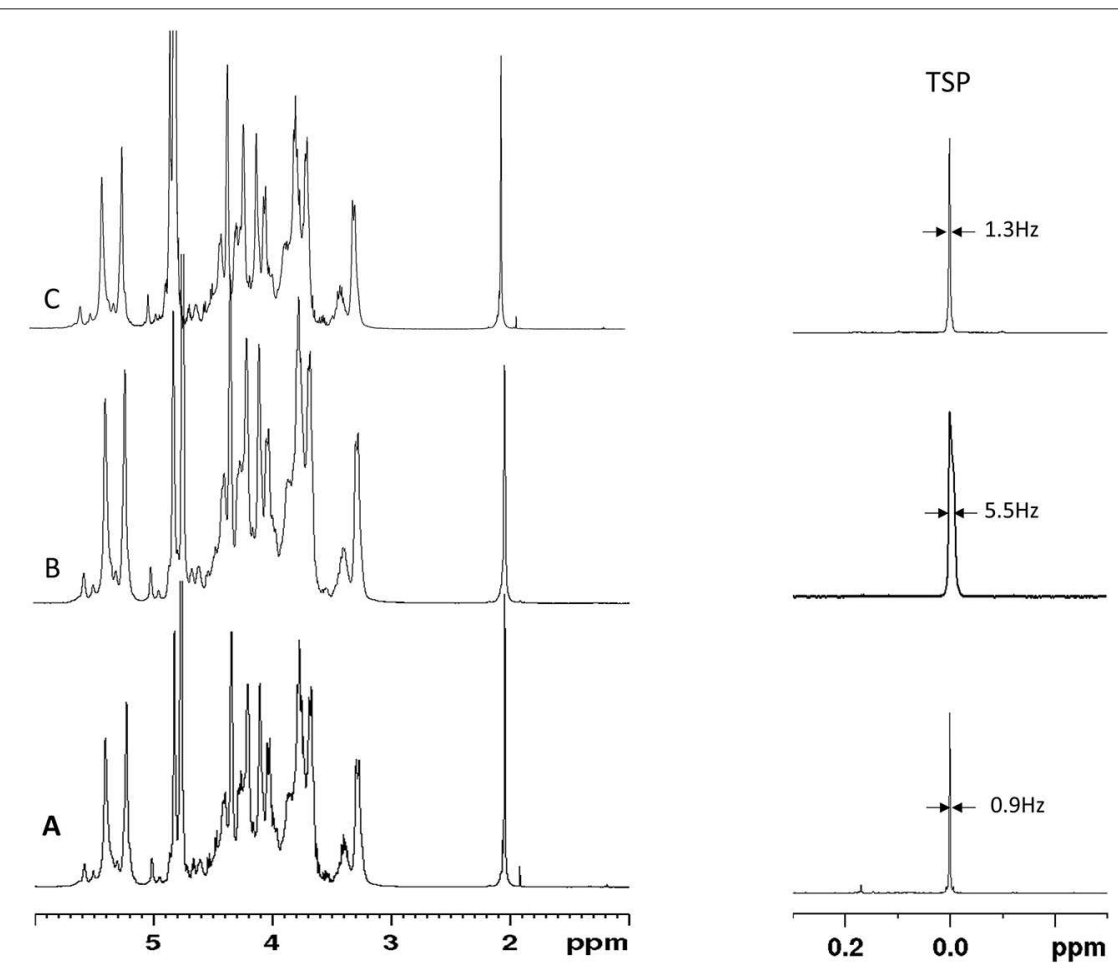

FIGURE 6 | Proton spectra of PMH sample provided by USP measured by Laboratory 1 (A) and Laboratory 2 (B,C). TSP signal and the corresponding width at half height is reported. 


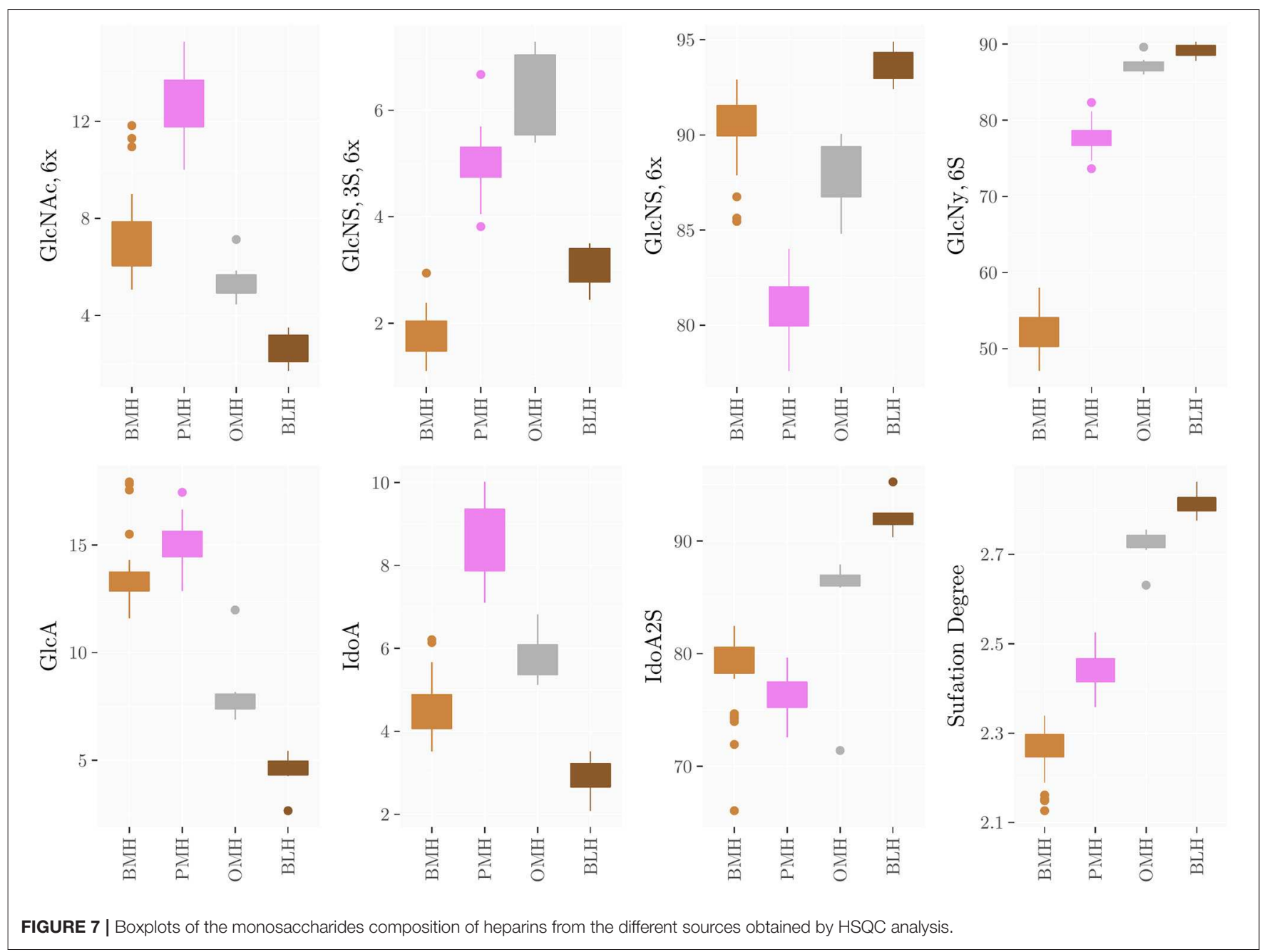

The method was applied to all groups of heparins and results are reported in Supplementary Materials (Supplementary Tables 9-21) and summarized in the box plots of Figure 7. Notably, the monosaccharide composition of both glucosamine and uronic acid shows some variability within the same heparin source that is attributed to the natural variability of the starting material and to the different process conditions used by manufacturers to purify heparin from the crudes. However, the process related variability is much lower than the differences found among the heparins of different origin (Figure 7). The strong reduction of 6-O-sulfation of $\mathrm{BMH}$ compared to the other heparin sources (GlcNy, $6 \mathrm{~S}<60 \%$ ), allows to easily differentiate $\mathrm{BMH}$ from other heparin types, similar to previously described carbon spectrum integration methods (8).

Importantly, differences which were not observable in the $1 \mathrm{D}$ proton spectra were clearly detected by the HSQC method. For instance, OMH, PMH, and BLH differ not only in the degree of acetylation of glucosamine residues $(\mathrm{PMH}>\mathrm{OMH}>\mathrm{BLH})$ but also in the glucuronic acid content and non-sulfated iduronic acid content $(\mathrm{PMH}>\mathrm{OMH}>\mathrm{BLH})$ (Figure 7$)$. The range of values of the corresponding residues can then be used to distinguish each heparin source.

A further level of characterization involved the quantification of disaccharide sequences and minor features, such as the heparin biological activity related glucuronic acid linked to 3-Osulfated glucosamine $\left(\mathrm{G}-\mathrm{A}^{*}\right)$ disaccharide that is a marker of the antithrombin-binding (ATb) pentasaccharide (23).

Because the $\mathrm{G}-\mathrm{A}^{*}$ sequence was identified exclusively in the active pentasaccharide sequence, $\mathrm{G}-\mathrm{A}^{*}$ can be considered the marker of the heparin ATb site. The amount of $\mathrm{G}-\mathrm{A}^{*}$ has a certain variability within each heparin source (Supplementary Tables 11, 14, 17, 20; Supplementary Figures 1, 2), which together with the molecular weight, may explain potency variability observable in commercial products. In contrast, the G-A* content varies considerably among heparin obtained by different sources. In particular, the highest amount of G-A* was observed in the PMH samples (from 1.9 to $3.4 \%$ ), while in the other species G-A* was always lower than $1.0 \%$, with the exception of one ovine sample for which the $\mathrm{G}-\mathrm{A}^{*}$ value reached $2.8 \%$. Moreover, in several $\mathrm{BMH}$ samples $\mathrm{G}-\mathrm{A}^{*}$ residue was not detectable (below 
LOD), possibly due to the presence of alternative AT-binding sequences (10).

In addition, the presence of 2,3-epoxy gluonic acid (epoxide) and galacturonic acid were observed and are known to be formed during the alkali treatment of heparin that occurs during the heparin purification process (24). Even if epoxide and galacturonic acid residues were not detected in many batches (Supplementary Tables 11, 14, 17, 20; Supplementary Figures 1,2), some samples contained levels of these unnatural residues which were not observable in proton NMR spectra. Notably, 15 of $39 \mathrm{BMH}$ samples contain galacturonic acid ranging from 0.9 to $9.8 \%$ and 4 of $39 \mathrm{BMH}$ samples contain epoxide (1.3to 4.8\%). These large amounts of chemically modified structures can affect not only the activity of heparin but possibly also the pharmacokinetic and other biological properties and therefore the control of epoxide and galacturonic acid process related impurities levels in the heparin API manufacturing process would be recommended.

\section{CONCLUSION}

In response to the FDA interest in considering reintroduction of bovine heparin drug product to the US market, there is a need to develop tests for the identity of the heparin animal and tissue origin. The method developed here, is an alternative to that proposed by ANVISA, that is able not only to distinguish $\mathrm{BMH}$ from $\mathrm{PMH}$, but also to confirm that the sample was not manufactured from other heparin sources such as bovine lung or ovine mucosa. The method, based on measurement of a proton NMR spectrum, is not much different from that present in both US and EU pharmacopeias for the identification of PMH heparin. A method utilizing the intensity ratios among selected signals was indeed already used in several pharmacopeia monographs to detect the presence of possible unknown contaminant (7). Here, a further proposed modification allows more different heparin types from potentially commercially viable animal sources to be distinguished, making clear the source of the product.

Nevertheless, overlapping signals on the proton NMR spectra prevent signals of minor structural signatures to be detected. For example, the presence of epoxidated or galacturonic acid residues cannot be easily observed in $1 \mathrm{D}$ proton spectra, while their signals are well resolved in the 2D HSQC spectra. The possibility to use the HSQC spectra, not only to assign 1D superimposed proton signals but also to quantify the relative abundance of each residue of glycosaminoglycans, was recently proposed by different groups $(17,18)$. These groups showed that a single HSQC analysis was able to provide the mono and disaccharide composition of heparin, including detection, and quantification of process related residues (i.e., epoxidation, galacturonic acid,

\section{REFERENCES}

1. Text on the WHO Medicines website. WHO Model List of Essential Medicine. Available online at: http://apps.who.int/iris/ bitstream/handle/10665/273826/EML-20-eng.pdf?ua=1 (accessed March, 2017). or residues generated by oxidative treatment) (24-26) establish the species and organ source of heparin and detect the presence of possible contaminants. The presence and the identification of the contaminant (OSCS) during the heparin crisis was indeed confirmed by HSQC analysis (4).

Even if 2D HSQC would be preferable in terms of amount of information obtained, the need for instruments equipped with high sensitivity probes (for example, cryogenically cooled probes) and for operators skilled in NMR, will make the application of the HSQC method difficult for many analytical laboratories. Although lower resolution and containing less information than 2D data sets, $1 \mathrm{D}$ proton-NMR data can be used to distinguish heparin types in a facile manner and is very similar to a method that is already required by several pharmacopeias and more widely applicable to an analytical laboratory. However, the increasing sensitivity and accuracy of NMR spectrometers and the availability of software which allows the complete automatization of the spectra processing and analysis have made the HSQC methodology a viable information value added alternative for many laboratories and may become more widely accessible in the future.

\section{ETHICS STATEMENT}

The study described in the manuscript does not involve human subjects.

\section{AUTHOR CONTRIBUTIONS}

LM, MG, DK, and RL contributed to planning and writing the paper. LM, MM, KS, MK and NP performed the NMR analyses. LM and MK performed the statistical analysis. All authors contributed to revision of the manuscript and read and approved the submitted version.

\section{FUNDING}

RL was supported by the US NIH in the form of grant \# DK111958, CA231074, HL125371, and HL094463.

\section{ACKNOWLEDGMENTS}

We thank Dr. Giovanni Boccardi for the useful discussion of results.

\section{SUPPLEMENTARY MATERIAL}

The Supplementary Material for this article can be found online at: https://www.frontiersin.org/articles/10.3389/fmed. 2019.00142/full\#supplementary-material

2. Barrowcliffe TW. History of Heparin. In: Lever R, Mulloy B, Page CP, editors. Heparin-A Century of Progress. Berlin/Heidelberg: Springer (2012). p.3-22. doi: 10.1007/978-3-642-23056-1_1

3. Schonberger LB. New variant Creutzfeldt-Jakob disease and bovine spongiform encephalopathy. Infect Dis Clin North Am. (1998) 12:11121. doi: $10.1016 / \mathrm{S} 0891-5520(05) 70412-8$ 
4. Guerrini M, Beccati D, Shriver Z, Naggi A, Viswanathan K, Bisio A, et al. Oversulfated chondroitin sulfate is a contaminant in heparin associated with adverse clinical events. Nat Biotechnol. (2008) 26:66975. doi: $10.1038 /$ nbt1407

5. Kishimoto TK, Viswanathan K, Ganguly T, Elankumaran S, Smith S, Pelzer $\mathrm{K}$, et al. Contaminated heparin associated with adverse clinical events and activation of the contact system. N Engl J Med. (2008) 358:245767. doi: 10.1056/NEJMoa0803200

6. Szajek AY, Chess E, Johansen K, Gratzl G, Gray E, Keire D, et al. The US regulatory and pharmacopeia response to the global heparin contamination crisis. Nat Biotechn. (2016) 34:625-30. doi: 10.1038/ nbt.3606

7. Keire D, Mulloy B, Chase C, Al-Hakim A, Cairatti D, Gray E, et al. Diversifying the global heparin supply chain: reintroduction of bovine heparin in the United States? Pharm Technol. (2015) 39:28-35.

8. Casu B, Guerrini M, Naggi A, Torri G, De-Ambrosi L, Boveri G, et al. Characterization of sulfation patterns of beef and pig mucosal heparins by NMR spectroscopy. Arzein Fors. (1996) 46:472-7.

9. Tovar AMF, Santos GRC, Capillé NV, Piquet AA, Glauser BF, Pereira MS, et al. Structural and haemostatic features of pharmaceutical heparins from different animal sources: challenges to define thresholds separating distinct drugs. Sci Rep. (2016) 6:35619. doi: 10.1038/srep 35619

10. Naggi A, Gardini C, Pedrinola P, Mauri L, Urso E, Alekseeva A, et al. Structural peculiarity and antithrombin binding region profile of mucosal bovine and porcine heparins. J Pharm Bioanal Anal. (2016) 118:5263. doi: 10.1016/j.jpba.2015.10.001

11. Guerrini M, Bisio A, Torri G. Combined quantitative ${ }^{1} \mathrm{H}$ and ${ }^{13} \mathrm{C}-\mathrm{NMR}$ spectroscopy for characterization of heparin preparations. Semin Thromb Hemostas. (2001) 27:473-82. doi: 10.1055/s-2001-17958

12. Thanawiroon C, Rice KG, Toida $\mathrm{T}$, Linhardt RJ. Liquid chromatography/mass spectrometry sequencing approach for highly sulfated heparin-derived oligosaccharides. J Biol Chem. (2004) 279:2608-15. doi: 10.1074/jbc.M304772200

13. Watt DK, Yorke SC, Slim GC. Comparison of ovine, bovine and porcine mucosal heparins and low molecular weight heparins by disaccharide analyses and 13C NMR. Carbohydr Polym. (1997) 33:5-11. doi: 10.1016/S0144-8617(97)00042-8

14. Fu L, Li G, Yang B, Onishi A, Li L, Sun P, et al. Structural characterization of pharmaceutical heparins prepared from different animal tissues. J Pharm Sci. (2013) 102:1447-57. doi: 10.1002/jps.23501

15. Farmacopeia Brasileira. 5a Edição, Segundo Suplemento. Heparina Sódica Bovina.

16. Guerrini M, Naggi A, Guglieri S, Santarsiero R, Torri G. Complex glycosaminoglycans: profiling substitution patterns by two-dimensional NMR spectroscopy. Anal Biochem. (2005) 337:35-47. doi: 10.1016/j.ab.2004. 10.012
17. Keire D, Buhse LF, Al-Hakim A. Characterization of currently marketed heparin products: composition analysis by 2D-NMR. Anal Methods. (2013) 5:2984-94. doi: 10.1039/c3ay40226f

18. Mauri L, Boccardi G, Torri G, Karfunkle M, Macchi E, Muzi L, et al. Qualification of HSQC methods for quantitative composition of heparin and low molecular weight heparins. J Pharm Biomed Anal. (2017) 136:92105. doi: 10.1016/j.jpba.2016.12.031

19. Aquino RS, Pereira MS, Vairo BC, Cinelli LP, Santos GR, Fonseca RJ, et al. Heparins from porcine and bovine intestinal mucosa: are they similar drugs? Thromb Haemost. (2010) 103:1005-15. doi: 10.1160/TH09-11-0761

20. Tovar AMF, Capillé NVM, Santos GRC, Vairo BC, Oliveira SN, Fonseca RJ, et al. Heparin from bovine intestinal mucosa: glycans with multiple sulfation patterns and anticoagulant effects. Thromb Haemost. (2012) 107:90315. doi: 10.1160/TH-11-07-0518

21. Casu B, Grazioli G, Guerrini M, Naggi A, Torri G, Oreste P, et al. Heparin-like compounds prepared by chemical modification of capsular polysaccharide from E. coli K5. Carbohydr Res. (1994) 263:271-84. doi: 10.1016/0008-6215(94)00172-3

22. Rudd TR, Gaudesi D, Skidmore MA, Ferro M, Guerrini M, Mulloy $\mathrm{B}$, et al. Construction and use of a library of bona fide heparins employing 1H NMR and multivariate analysis. Analyst. (2011) 136:13809. doi: $10.1039 / \mathrm{c} 0 \mathrm{an} 00834 \mathrm{f}$

23. Casu B. Structure and active domains of heparin. In: Garg HG, Linhardt RJ, Hales CA. Chemistry and Biology of Heparin and Heparan Sulphate. Oxford: Elsevier (2005). p. 1-28. doi: 10.1016/B978-008044859-6/50002-2

24. Rej RN, Perlin AS. Base-catalyzed conversion of the a-L-iduronic acid 2-sulfate unit of heparin into a unit of a-L-galacturonic acid, and related reactions. Carbohydr Polym. (1990) 200:43747. doi: 10.1016/0008-6215(90)84209-D

25. Beccati D, Roy S, Yu F, Gunay NS, Capila I, Lech M, et al. Identification of a novel structure in heparin generated by potassium permanganate oxidation. Carbohydr Polym. (2010) 82:699-705. doi: 10.1016/j.carbpol.2010.05.038

26. Chen Y, Ange KS, Lin L, Liu X, Zhang X, Linhardt RJ. Quantitative analysis of the major linkage region tetrasaccharides in heparin. Carbohydr Polym. (2017) 157:244-50. doi: 10.1016/j.carbpol.2016.09.081

Conflict of Interest Statement: The authors declare that the research was conducted in the absence of any commercial or financial relationships that could be construed as a potential conflict of interest.

Copyright (C) 2019 Mauri, Marinozzi, Phatak, Karfunkle, St. Ange, Guerrini, Keire and Linhardt. This is an open-access article distributed under the terms of the Creative Commons Attribution License (CC BY). The use, distribution or reproduction in other forums is permitted, provided the original author(s) and the copyright owner(s) are credited and that the original publication in this journal is cited, in accordance with accepted academic practice. No use, distribution or reproduction is permitted which does not comply with these terms. 